\title{
Characterizing researchers to study research funding agency impacts: The case of the European Research Council's Starting Grants
}

\author{
Duncan Thomas* and Maria Nedeva \\ Manchester Institute of Innovation Research, Manchester Business School, The University of \\ Manchester, Manchester, M13 9PL, UK \\ *Corresponding author.Email: duncan.thomas@mbs.ac.uk
}

\begin{abstract}
We describe the development and testing of a framework to characterize researchers individually (a profile) and in aggregate (as types) at the first stage, baseline step of a controlled, two-stage study of public research funding agency impacts. Our framework characterizes researcher attitudes and attributes, and conditions and opportunities experienced, addressing: 'demographic' factors; researcher 'approach'; and 'standing' (organizational career, knowledge community career, and local and national research environment aspects). This integrated demographic-approach-standing (DAS) framework is tested using a survey of 184 applicants to the inaugural, 2007 call for the European Research Council (ERC) Starting Grants (StG). Successful applicants are characterized to match-pair with a control group of quality-screened unsuccessful applicants. Given the inherent difficulty to identify in advance the 'frontier' researchers the ERC aims to fund with its StG, we characterize 'frontier-potential' factors that might lead researchers later to become regarded as frontier. We develop researcher types using several of our framework elements: researcher intellectual field mobility; novelty and risk-taking; independence; output productivity; and local research workplace standing. We find a variety of grantee types, but primarily not yet independent researchers whose 'standing' could be impacted upon by the early-career StG scheme. Lastly, we suggest impact pathways between types we could capture following a second stage survey, and discuss limitations

to our framework including revising it to characterize better local research environment aspects.
\end{abstract}

Keywords: funding agency impacts; European Research Council; characterizing researchers; frontier research.

\section{Introduction}

In this article, we develop a researcher characterization framework to study the impact of research funding agency schemes, using the case of the European Research Council (ERC) early-career Starting Grants (StG). We first discuss our rationale for developing a new framework, outline the StG's objectives and conditions then review relevant previous approaches to characterization. We present our integrated framework's three aspects to characterize researchers: 'demographic' factors; researcher 'approach' attitudes and attributes; and 'standing' conditions and opportunities experienced that span organizational career, knowledge community career, and local and national research environment aspects. We then conduct a first stage, baseline application of this demographic-approach-standing (DAS) characterization framework via an online questionnaire survey of 184 researchers that applied to the inaugural, $2007 \mathrm{StG}$ call. This addresses both successful applicants and a control group of unsuccessful applicants that passed a quality threshold (Stage 1 of the application process). We also produce researcher 'types' to categorize researchers in aggregate to explore the ERC's selection of grantees, and to suggest impact pathways between types that we could capture if a second stage survey was later conducted. We close by highlighting limitations and discussing how the 
DAS framework might be enhanced, particularly to characterize better local research environment aspects.

\subsection{Rationale for a new characterization framework}

Public research funding agencies need to support research with particular properties. They are increasingly subject to evaluations of their goals as more public research funding is allocated via competitive, externally peer-reviewed mechanisms (Bourke and Butler 1999; Langfeldt 2001; Laudel 2006). This holds true for the ERC, a panEuropean research funding agency claiming to support excellent 'frontier' research, and the subject of intense interest since its establishment in 2007 (Nedeva and Stampfer 2012).

Generally research funding agencies support research with particular qualities via three key mechanisms: selection of people and research projects with certain potential; conditions of funding and funding grants; and accountability practices (Nedeva 2012). Here we focus on the selection of ERC-funded researchers with specific characteristics because we believe research with particular qualities is carried out by researchers with definite inclinations operating within certain settings.

Three frameworks to characterize researchers have typically been used in this area: bibliometric measurements of research outputs (e.g. Böhmer and von Ins 2009; Klavans and Boyack 2011; Chen 2012); mapping creative inclinations using psychological approaches and assumptions (e.g. Boyatzis 2008; Charlton 2009; Ravilious 2011); and science policy-type studies of research environment, organizational and institutional factors as proxies or predictors of researcher qualities (e.g. Jordan 2006; Bozeman and Gaughan 2011). Each has strengths but a weakness has been their typical use in isolation rather than to characterize a comprehensive range of researcher facets. Instead we develop an integrated framework to characterize researchers, to discern whether a funding agency has selected researchers with the potential to carry out and exploit research with particular qualities.

\subsection{The ERC, the StG, and frontier research}

The ERC launched in 2007 with a budget of $€ 7.5$ billion, around $15 \%$ of the $€ 50.5$ billion EU Seventh Framework Programme (FP7, 2007-13). The ERC claimed to be 'the first European funding body set up to support investigator-driven frontier research' and stated 'scientific excellence' was its 'sole criterion' when selecting research to fund. ${ }^{1}$ One of its two inaugural funding instruments was an early-career researcher funding scheme, the StG. Presenting the context for its StG the ERC described the European research landscape as leading to a 'dramatic waste of research talent' with 'insufficient opportunities for young investigators to develop independent careers', delays in the 'emergence of the next-generation of research leaders' and consequent brain drain out of Europe. ${ }^{2}$ The StG therefore offered resources and conditions for 'up-and-coming research leaders...to establish or consolidate a proper research team and...start conducting independent research in Europe'. ${ }^{3}$ The $\mathrm{StG}$ scheme funds research projects of up to $€ 2$ million over up to 5 years, and is portable to any research workplace within Europe. ${ }^{4}$ There are no applicant age restrictions just an early-career stage cut-off. ${ }^{5}$ Since its inception the StG has been oversubscribed ${ }^{6}$ showing clear demand for this kind of funding scheme.

The ERC's declared aims are ambitious and challenge traditional ways in which the impact of public research funding agencies has been studied. The ERC aims to change researchers, to accelerate their transition to positions of independence and leadership, thus to affect the science system itself not just cause socio-economic impacts. However its aims, whether achieved or not, are mediated through multiple aspects - research content, researchers, research organizations, and national research landscapes - over which it has limited control. Additionally 'frontier research' is difficult to attribute as an outcome of ERC funding due to time lag before its occurrence and many potentially intervening factors to consider.

Moreover in European policy usage 'frontier research' is more a metaphor than a definition. For the ERC the term emerged as a compromise from high-level expert input into the ERC's establishment (Nedeva 2012) becoming defined as 'a new understanding of basic research' involving 'research at and beyond the frontiers of understanding', lacking 'disciplinary boundaries', and of 'critical importance to economic and social welfare' yet still 'an intrinsically risky venture'. ${ }^{7}$ The term also encapsulated a culture shift away from increasingly irrelevant basic/ applied and disciplinary distinctions that fail to capture the more boundaryless, 'multi-, inter-, or transdisciplinary' properties of modern research activities (EC 2005: 18).

Some key properties of frontier research seem interchangeable with existing terminology of 'pioneering', 'path-breaking', or 'highly creative' research and researchers (Heinze and Bauer 2007; Heinze 2008; Charlton 2009; Heinze et al. 2009; Shapira et al, 2009). The difficulty is to confirm fully these properties at the moment of funding selection, as they can only be confirmed ex post following impacts for science, technology, or wider society (see Basalla 1988; Rycroft and Kash 1999) and numerous social, economic, political, and institutional factors confound ex ante identification (Polanyi 1969; Whitley 2000; Heinze et al. 2007).

Noting these complications we focus on promising preconditions - what we call frontier-potential - that is, characteristics that might increase the likelihood of researchers becoming later regarded as 'frontier'. We also address attribution issues by characterizing unsuccessful but 
quality-screened StG applicants to match-pair with grantees, thus attempting a ceteris paribus study of impact.

\section{Review of previous research}

Researchers intersect various components of the science system upon which research funding agencies can have impact. Accordingly, we reviewed previous research on characterizing researchers, research environments, and research funding schemes.

\subsection{Characterizing researchers}

Researchers we would label as 'frontier-potential' have typically been characterized by exploring bibliometric, psychometric, research environment, organizational, and institutional factors (see Jordan et al. 2003; Jordan 2006; Boyatzis 2008; Neufeld and von Ins 2011). Some researchers have used approaches in isolation while others have sought to use combined methods (see Heinze et al. 2009; Klavans and Boyack 2011; Chen 2012; Youtie et al. 2012).

Bibliometric characterization as applied to studying research funding agency impacts has had drawbacks. Backward-looking approaches may be unable to highlight frontier-potential and can fail to distinguish between researchers who share productivity and citation strength characteristics. Grantee and control matched-pair bibliometrics that have controlled for researcher quality have been unable to discern suitable dimensions of variety to distinguish between researchers when successful and similar quality unsuccessful applicants to the same scheme are considered (Melin and Danell 2006; Neufeld and von Ins 2011). The typical fallback has been to conduct supplementary qualitative interviews to explore additional causal factors that might explain say, funding scheme application success or peer recognition of certain individuals as 'path-breaking' or 'highly creative'.

Outside of specific application to research funding impact studies, promising bibliometric approaches exist. Klavans and Boyack (2011) have used bibliometric analysis to show extremely prolific, so-called 'superstar' scientists' impact upon the science system by driving the life cycles of new scientific paradigms and interconnections between related research lines. Chen (2012: 431) has modelled the potential of scientific articles to vary research field intellectual structure based on introducing new boundary-spanning connections.

Psychometric approaches, including those addressing social and emotional intelligence aspects, leadership, or charisma (Boyatzis 2008; Antonakis et al. 2011; Schyns et al. 2011) used in isolation pay undue attention to researcher psychology while overlooking other enabling, institutional and organizational factors, and conditions beyond the control of a researcher. ${ }^{8}$ Isolated consideration of generic capacities or technical competencies - ability to identify significant research directions, networking and dissemination skills, career planning, research outcome monitoring, and project management skills and teamwork (Rowley and McCulloch 1999; Lee 2009; Nedeva 2009)do not distinguish frontier-potential as these are characteristics common to most competent researchers beyond an early post-doctoral career stage (Nedeva 2009).

Exceptional characteristics are more relevant, including passion for a research subject, being a good writer, having broad knowledge, being highly creative and overcoming bureaucratic barriers with an attitude of 'creative dissent' (Braben 2004). Academic training can stifle such traits by rewarding perseverance and sociability more than high creativity (Charlton 2009). Path-breaking individuals often have to be independently minded and intrinsically motivated (Udwadia 1990; Vallerand et al. 1992) to pursue new, unexpected knowledge (Heinze et al. 2007: 129) with a 'maverick' indifference to adverse consequences for their career (Dowd and Kaplan, 2005: 709) perhaps seeing themselves as 'winning underdogs' (Bennis and Biederman 1997; Jordan et al. 2003). They need a risk-taking orientation and an atypical high tolerance for failure, contradictions, and uncertainties (Heinze and Bauer 2007: 814) and for orthodox processes whereby new creativity can challenge established knowledge and research community standards of excellence and scientific validation (Whitley 2000; Heinze et al. 2007: 128) that favour conformity over dissent (Polanyi 1969). Recognition and rewards can be absent. Typical peer accolades, such as special prizes and awards, are 'extremely selective' due to conformity and resource limits meaning fewer prizes are available than there are creative accomplishments to recognize (Heinze et al. 2007: 131).

High, path-breaking creativity involves multidisciplinarity and network brokerage - drawing knowledge and insights from differing technological and research domains, and communicating with peers from multiple research fields (Simonton 1999, 2004; Heinze and Bauer 2007; Nemet and Johnson 2011; Schilling and Green 2011) to open opportunities to combine multiple approaches into novel ideas (Burt 1992, 2004; Heinze and Bauer 2007: 812). Such cognitive flexibility may be how top scientists' bridge and traverse diverse research lines and fields (Klavans and Boyack 2011) and exposure to diverse ways of thinking is ostensibly an underlying rationale for recent policy promotion in Europe of greater researcher geographic mobility (Van Bouwel et al. 2011).

Overall we see a multi-dimensional picture of a 'frontier-potential' researcher from which we extract five of the six researcher attitude/attribute 'approach' aspects in our DAS framework, and one 'standing' aspect: geographic and workplace mobility; cognitive mobility (number of significant intellectual field changes and education track record atypicality); novelty/risk-taking levels; indifference to job security; and atypicality of recognition/ reward approach (namely targeting in which journals to 
publish, looking for divergence from high impact/citation motivations towards social, economic, political, public understanding, and science system impacts; see Small 2004; Small et al. 2008); and receipt of accolades.

\subsection{Characterizing research environments}

Publicly funded researchers have both organizational and knowledge community careers (Dill 1982; Nedeva 2011, 2012). Organizational careers exist within the 'research space' of the host research organization workplace and its funding from local, national, and international research agencies. They involve research, teaching, and supervision activities, and host organization resources and strategies that bound researcher autonomy, employment conditions, team sizes, and availability of research-related infrastructure. Knowledge community careers exist within an overlapping but geographically broader 'research field' made up of 'pools' of accumulated knowledge, and collaborations with trans-national knowledge community peers, involving academic service and the production, dissemination, and peer recognition of research (e.g., via prizes, awards, and fellowships).

Previous studies have not correlated an integrated assessment of these aspects with frontier-potential outcomes but have noted influential factors (Heinze et al. 2009: 610). Small group sizes, multi-disciplinary researcher skill sets, research leaders committed to diverse research activity, diversity in researcher talent recruitment, and flexible research resources (including core institutional funding) are important, albeit to varying degrees for differing research fields (Andrews 1979; Dill 1985; Jordan et al. 2003; Hage 2006; Heinze et al. 2009: 610-613; Bauer et al. 2012).

Some of these characteristics also overlap with the wider universe of research organization performance. ${ }^{9}$ In most research environments individuals and groups undertake portfolios of research activity, making uniform assessments misleading. It is possible however to characterize collections of activity: Larédo and Mustar (2000) identified laboratory activity profiles (orientation of activities towards academic, service, training, and economic goals); Clausen et al. (2012) looked at research unit characteristics in emerging scientific fields (field coverage, staff background, activity profiles, internal and external organizational barriers and support, and funding portfolios); and Jordan (2006) has suggested how activity portfolios relate to different scientific advances, guided by research manager scale/scope of research choices, and acceptance of risk/reward payoffs for radical advances in particular. ${ }^{10}$

Within our current survey-based approach, these research environment characterization aspects were difficult to operationalize, as they are not attributes of an individual respondent but rather their perception of contextual conditions and opportunities. We attempted to capture some characteristics in the 'research environments' sub-component of our framework-namely, resource sufficiency, time for research, researcher independence, researcher team size, and perceived local workplace reputation and performance. However, future enhancement of our framework could better map strategic research environment and group factors and their interaction with individual researcher characteristics (see Section 5).

\subsection{Characterizing research funding schemes}

Research funding agency conditions and processes can affect frontier-potential. External peer review can systemically discriminate against novel, early-stage, high-risk research proposals. Peer reviewers can find them less mature and 'elegant' than already proven research ideas (Lamont 2009: 162-163). Unanimous, compromise, or consensus-based peer review can prefer mainstream research (Heinze 2008: 303) as 'controversy over applications in the decision-making process' is rarely seen 'as a signal that a proposal, by triggering such debate, was particularly worth funding' (Heinze 2008: 316). Leading national research funders may find it difficult to justify funding frontier research with 'uncertain, distant, and often negative' returns when safer research exploiting 'existing competences, technologies, and paradigms' promises 'positive, proximate, and often predictable' returns - meaning safe ideas are often funded rather than the 'best' ones (Heinze 2008: 302; see also Bourke and Butler 1999; Langfeldt 2001; Shapira and Kuhlmann 2003; Laudel 2006). Short-term, external, competitive funding can lead to risk-aversion where long-term, institutional funding can encourage high-impact, explorative, frontier-potential activity. Whether 'elite' or 'normal' scientists are the target funding recipients, whether funding supports multi-disciplinarity, and how originality, riskiness, and track record criteria are balanced are also important (Heinze 2008: 304-306).

Overall from this material we drew our final 'approach' element - atypicality of project funding track record, to flag researchers less supported by, in particular, national funding agencies that may represent the above barriers to frontier-potential research activity.

\subsection{Characteristics from previous funding scheme evaluations}

We also looked at selected funding scheme impact evaluations. First, we noted Melin and Danell's (2006) assessment of a prestigious Swedish Foundation for Strategic Research funding scheme for highly talented junior scientists, looking at 20 funded and 20 non-funded applicants. Four years after the funding decision the non-funded group had lost research focus and direction and had had to substitute for the grant with multiple, sub-optimal funding sources that left them unable to undertake 
high-risk research. In contrast grantees had focused and strengthened their research profiles (Melin and Danell 2006: 705-710). Second we looked at Shapira et al. (2009) revisiting an evaluation by the National Research Council (NRC 2006) of the Markey Scholars programme that provided long-term financial support to outstanding, young biomedical researchers in the USA. Grantee and two matched control groups were used-top ranking controls, and lesser but still competitive controls (Shapira et al. 2009: 4). The top-ranked control group were similar to grantees on faculty position and publication success, but grantees were in better universities, had generally received tenure, and had more promotions and research grants (Shapira et al. 2009). Generally these evaluations suggested prestigious funding scheme impacts on research direction and resource autonomy, risk-taking, organizational career progress, and workplace quality - all of which we incorporated into our DAS framework.

We also studied an evaluation of the German Research Foundation's Emmy Noether-Programme (ENP), preparing young, excellent scientists for professorships by enabling them to lead a research group atypically early in their career (Neufeld and von Ins 2011: 32). This ENP evaluation challenged previous expectations (by Van den Besselaar and Leydesdorff 2009) that grantee applicants should have more publications and higher citations than eventually rejected funding scheme applicants. As with Shapira et al. (2009) productivity/citation differences disappeared when successful applicants were compared with similar quality rejected applicants. Follow-up interviews indicated grantees got professorships earlier than controls, and had more autonomy (Neufeld and von Ins 2011)-i.e., strong organizational career impacts (promotion, independence) and weak knowledge community career impacts (productivity, prestige). ${ }^{11}$

Lastly, we explored control group design evaluations of an early-stage, high-risk industry R\&D funding scheme, the US Advanced Technology Program ${ }^{12}$ (ATP) (NIST 2003, 2005, 2006; also Feldman and Kelley 2001; Kerwin and Campbell 2007). Like Melin and Danell (2006) they suggested non-funded researchers drifted towards reduced scope, lower risk projects; as per Shapira et al. (2009) they found grantees attracted unexpected, additional research funding by virtue of having received a prestigious granta 'halo' effect (NIST 2003; Feldman and Kelley 2001). The ATP evaluations also highlighted a time factor-grantee projects had a delayed, but overall more durable socio-economic impact compared with non-funded projects (Feldman and Kelley 2001; NIST 2003, 2005). ${ }^{13}$

From this material we included output productivity and a time dimension to our researcher novelty/risk-taking 'approach' component (self-reported uptake period for research outcomes that respondents' expected from academic and non-academic users). These studies also suggested funding scheme impacts for our framework design: potentially greater risk-taking/novelty by grantees; attraction of additional funding by grantees ('halo' effect); grantees being hosted at higher reputation/performance workplaces and having better organizational career conditions and prospects; and non-funded control group researchers pursuing lower risk, less focused research than originally planned, via a medley of less than ideal, alternative funding sources.

\section{Framework and impact assumptions}

Our final DAS framework included 23 elements, shown in Table 1, registered for each surveyed respondent.

We believe our DAS components might interact with $\mathrm{StG}$ funding in the following ways. First, all four 'demographic' variables might mediate the breadth and depth of StG impacts (although 'demographic' remains an independent variable, unalterable by the $\mathrm{StG}$ ). Gender (D1) is a likely mediator of researcher opportunity (e.g., see Bozeman and Gaughan 2011). Researcher age (D2) and dependent responsibilities (D3) may also affect StG impact-related researcher career choices and opportunities (Laudel 2005; Laudel and Gläser 2008) and StG impacts may vary by research domain [D4, where we used ERC categories: life sciences (LS); physical sciences and engineering (PE); and social sciences and humanities $\left.(\mathrm{SH})^{14}\right]$.

The StG funds all research domains, challenging us to register standardized researcher characteristics across disparate fields. We used both relative measures (self-reported researcher perceptions of themselves compared with their research field peers and/or career stage) and absolute ones we later manually checked across domains to accommodate domain-specific variances. Consequently our findings apply specifically to the 2007 call, StG 'first cohort' of researchers who responded to our survey, and are not yet fully representative or generalizable. ${ }^{15}$ Their significance is also affected both by the small number of survey responses and the self-reported nature of the data.

For 'approach' the material we reviewed (see Section 2) suggested these aspects would be difficult to change via a single funding intervention like the StG. Accordingly, we took 'approach' as an independent variable - albeit we could register later changes, and we believe researcher 'approach' will mediate StG impacts (as per 'demographic'). To avoid loaded survey questions our 'approach' aspects were proxies for key characteristics. For instance whole career (study and research) geographic and workplace mobility was our proxy for exposure to different research environments, scientific cultures, and research traditions; job security indifference we inferred from self-reported employment contract length changes between previous and current workplaces (e.g., we could detect researchers atypically moving from permanent to non-permanent contracts). We analysed respondents' research project funding track record to flag atypically low levels of support from their main national research 
Table 1. DAS framework to characterize the 2007 call StG grantee and control group survey respondents

Element Description

Demographic

D1. Gender

D2. Age bracket

D3. Relationship/dependents status

D4. Research domain

Approach A1. Geographic and workplace mobility

A2. Cognitive mobility

A3. Perceived research novelty and risks

A4. Job security indifference

A5. Atypicality of project funding track record

A6. Atypicality of journal targeting approach

Standing Organizational career

S1. Ability to raise needed research resources

S2. Time for research

S3. Long-term research direction independence

S4. Personal funding situation

S5. Own team size growth

Knowledge community career

S6. Amount of academic service tasks undertaken

S7. Prestige of academic service

S8. Number of research collaborators

S9. Output productivity

S10. Number of accolades

S11. Article acceptance rate

Research environments

S12. Perceived local workplace reputation and performance

S13. Assumed research performance/ambition of national setting
Female or male

Respondent's reported age relative to the survey responses distribution for their own research domain

Combined measure of respondent's reported long-term relationship status (married/equivalent or not) and dependent caring responsibilities

Research domain, from ERC categories-LS, PE, SH

Combined measure of number of countries, and research workplaces worked in, during respondent's entire study and research career to date

Combined measure of reported number of significant changes of intellectual field during respondent's entire study and research career to date, and atypicality of respondent's study track record (undergraduate, postgraduate, doctoral, and more advanced degrees)

Combined measure of perceived novelty and risk level of respondent's ERC StG application, with self-reported research output success and applicability risks for their most important research project during past 2 years

Reported employment contract length (job security) change after respondent's most recent workplace move

Divergence from typical pattern of overall response set, for proportion of respondent's research project portfolio supported by their main national funder

Divergence from typical reasons for choosing in which journal to publish (journal reputation and impact factor considered important but not essential)

Combined respondent's opinions on lack of internal and external research resource constraints, including for essential international conferences and international research visits

Percentage of work time spent on research, relative to typical levels for respondents in own research domain, and if lack of research time was a constraint

Reported research direction freedom and job security sufficient to undertake long-term research activity and planning

Opinion of size of own funding amount for most important research project of the past 2 years relative to peers in own research field, and the actual amount (in Euros) compared with amounts observed for the overall respondent set

Change in proportion respondent's research team size represents out of their reported overall laboratory/department size, after most recent workplace move

Combined measure of amount of professional associations joined, reviewing and editorial activities undertaken, funding and expert panels served on, conferences organized, and fellowships received, relative to the overall response set

Opinion on how prestigious respondent's self-reported most important academic service is perceived to be by peers in their own research field

Absolute and relative (self-reported, relative to peers in own research field) number of regular research collaborators

Overall output productivity (self-reported, relative to both current career stage and the perceived typical level for research field peers)

Combined measure of number of patents (direct/indirect), prizes/special awards, and prestigious fellowships/equivalent compared with the overall response set

Percentage of articles submitted in the past 2 years to respondent's 'first choice' journal that were finally accepted, relative to own research domain

Combined measure of respondent's opinions on whether their research workplace is the best place in the world to do their research, has an outstanding international reputation, and has excellent scientific performance

Proxy classification (Tier 1, 2, 3) based on nation's gross expenditure on R\&D (GERD) as a percentage of gross domestic product (GDP) in 2008, number of full-time equivalent researchers in 2008, and national success rates (up to 2010) for both 'starting' and 'advanced' ERC grant applications 
funding agency, as a proxy for non-mainstream funding, and similarly we asked about journal targeting approaches to flag researchers who assigned atypically low importance to journal reputation and impact factors. ${ }^{16}$

'Standing, ${ }^{17}$ we considered most susceptible to StG impacts - from the funding duration, funding amount, promise of researcher autonomy, apparent prestige, and so on-and took it as our dependent variable. We believe receiving a StG would affect organizational and knowledge community career 'standing'. Local and national research environment 'standing' however are not directly mutable attributes or attitudes of a researcher but rather researchers' perceptions of experienced local conditions and opportunities (S12) and a non-survey, proxy indicator of national setting research performance and ambition (S13, related to national success rates in winning ERC grants, ${ }^{18}$ from Braun 2012). Local environment (S12) is a composite indicator of multiple researcher perceptions to increase reliability: perceived goodness of fit between research topic and research workplace conditions/ opportunities, and perceived international reputation and scientific performance of the host research workplace. Our understanding is not that these are attitude/attribute characteristics of a researcher to be directly affected by a StG but rather are experienced conditions/opportunities that could be internally re-negotiated (improved) given the reputational and resource capital likely afforded by a $\mathrm{StG}$ - or a researcher could exploit the StG's portability and move externally to a different workplace to secure better conditions.

\section{Applying the DAS framework}

Individual DAS profiles were registered for each survey respondent to provide a baseline for our intended study of $\mathrm{StG}$ impact. Our methodology was then to anticipate a later second stage, repeat survey and characterization of the exact same respondents. This would allow us to attribute later change of characteristics to $\mathrm{StG}$ impacts. Comparison of before/after states of each respondent would be more robust by creating matched-pairs of successful (grantee) and unsuccessful but quality-screened (control group) researchers sharing identical values for as many DAS elements as possible. All other things being equal, the key distinction between them should be that one side of a pair (the grantee) won a StG whereas the other (the control) did not. Later divergence in DAS characteristics should then be attributable as StG impacts. We also used a smaller selection of our DAS elements to characterize researchers in aggregate into types based on selected 'approach' and 'standing' dimensions. This allowed us to explore what kinds of researcher the ERC selected with its 2007 call StG, and to suggest credible 'impact pathway' movements between researcher types we might later expect.

\subsection{Data collection, response matters, descriptive information}

Our online questionnaire survey of ERC StG first cohort (2007 call) applicants targeted successful applicants (grantees) and a control group of unsuccessful applicants who passed the ERC's quality threshold for the 2007 call (Stage 1 of the application process ${ }^{19}$ ).

There were 276 potential respondents in our grantee respondent group and 105 in our control group, making 381 in total. ${ }^{20}$ Our questionnaire had 86 questions across 7 sections: basic personal information; recent funded research activities; current and previous research workplace features; opinions about research funders; number of research collaborators; details of research outputs; and aspects of respondents' ERC StG application. The survey was non-anonymous and ran for 3 months (December 2010 to February 2011).

The overall response rate was $48 \%$ with 184 usable responses. The response rate for grantees $(50 \% ; 138 / 276)$ was higher than for the control group $(44 \% ; 46 / 105)$; $39 \%$ of responses were LS researchers (cf. $41 \%$ in the original sample), $43 \%$ were PE (equal to the sample), and $17 \% \mathrm{SH}$ (cf. $16 \%$ in the sample). Respondents ranged from 31- to 46-year olds, covering most of the age variety of the original sample; $29 \%$ of respondents were female and $71 \%$ were male, similar to the known gender breakdown in the grantee sample $(27 \% / 73 \%)$. Additional descriptive information is in Table 2.

Overall we registered a spectrum of characteristics but generally respondents were high calibre for supposed early-career researchers. ${ }^{21}$ The control group was a reasonable quality match for the grantees - an important pre-requisite of our grantee/control matched-pair methodology.

\subsection{Characterizing researcher types}

We began with 'approach' types, and the intellectual field mobility sub-element of cognitive mobility (A2). After reviewing the distribution of grantee and control responses, we took 0-2 significant changes of intellectual field during the respondent's entire work/study career to date as 'low' or 'settled'; three or more as 'high' or 'nomadic'. We cross-tabulated with $\mathrm{A} 3$, perceived research novelty and risk-taking, labelling 'low' or 'medium' novelty/risk-taking as 'moderate'; 'high' as 'radical'. Four 'approach' types were created: settled-moderate; settled-radical; nomadicmoderate; and nomadic-radical.

For our 'standing' types we first addressed 'researcher independence' - composed of the following strongly positively correlated organizational career 'standing' elements: ability to raise needed resource resources (S1); long-term research direction independence (S3); and personal funding situation (S4). 'Low' or 'medium' values we labelled 'dependent'; 'high' or 'very high' as 'independent'. Second, we took the knowledge community career element 
Table 2. Descriptive information about the 2007 call StG overall survey respondent set

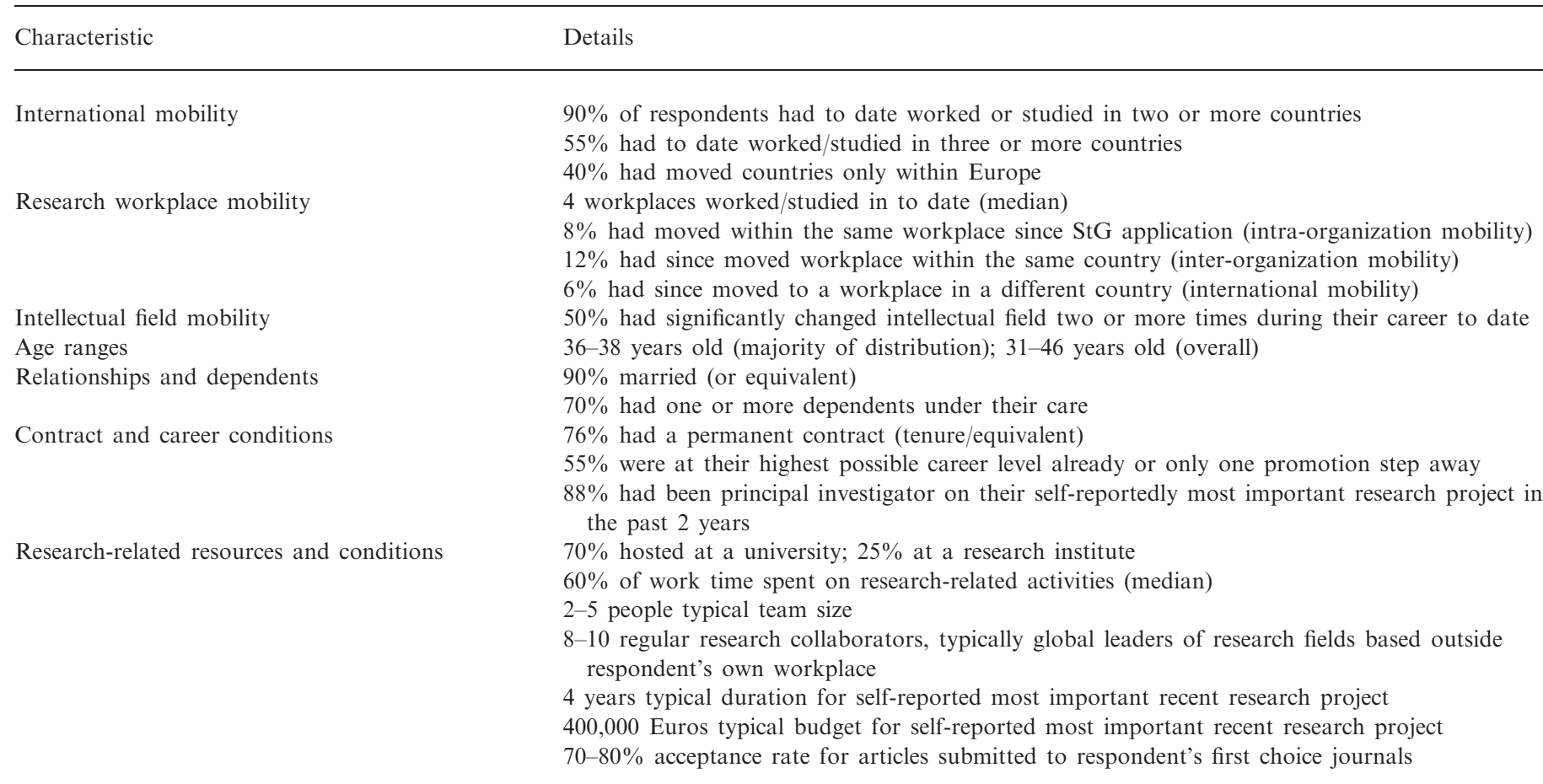

Table 3. Percentages of 2007 call StG grantees categorized into 'approach' and 'standing' types $(n=78$, missing $=60)$

Standing

\begin{tabular}{llll}
\multicolumn{4}{c}{ Approach } \\
\hline Settled-moderate (\%) & Settled-radical (\%) & Nomadic-moderate (\%) & $\begin{array}{l}\text { Nomadic-radical } \\
\text { ('maverick') (\%) }\end{array}$
\end{tabular}

$\begin{array}{lr}\text { Dependent-unprolific-normal } & 24.4 \\ \text { Dependent-prolific-normal } & 6.4 \\ \text { Dependent-unprolific-elite } & 7.7 \\ \text { Dependent-prolific-elite } & 2.6 \\ \text { Independent-unprolific-normal } & 9.0 \\ \text { Independent-prolific-normal } & 1.3 \\ \text { Independent-unprolific-elite } & 3.8 \\ \text { Independent-prolific-elite } & 3.8\end{array}$

'output productivity' (S9)_respondent's perceived productivity relative to both their current career stage and what they considered typical in their research field. ${ }^{22}$ 'Low' values we labelled 'unprolific'; high as 'prolific'. Third, we used self-reported local workplace reputation and performance (S12) taking 'very low', 'low', and 'medium' values as 'normal', 'high', and 'very high' as 'elite'. ${ }^{23}$ We therefore had one aspect from each sub-component of 'standing' giving us a spectrum of types from 'dependent-unprolific-normal' to 'independent-prolific-elite', and preparing the ground for later study of three $\mathrm{StG}$ impacts clearly intended by the ERC - on researcher independence, on researcher productivity, and on quality of local research environment.
Table 3 shows the overall percentage distribution of $\mathrm{StG}$ grantee respondents we could categorize into these 'approach' and 'standing' types.

Echoing these figures, when grantees were categorized using just 'standing' types, the majority $(39.3 \% ; 35 / 89)$ were 'dependent-unprolific-normal'. This suggests that with its 2007 call StG the ERC mainly funded a researcher type it intended to - i.e., those yet to make the transition to organizational career independence, yet to achieve (output-related) prominence in their knowledge community career, and not yet located in the best research environment for their particular research. The ERC also funded other 'standing' types, including 'independent-prolific-elite' researchers - a small minority here $(4.5 \% ; 4 / 89)$ 
but still perhaps not ideal targets for a 'starting grant' scheme.

The ERC funded various researcher 'approach' types, seemingly a sensible way to support a portfolio of risks and returns, avoiding a 'one size fits all approach' (Jordan 2006) and preserving variety in the science system. At the same time the majority of grantees whose 'approach' we classified in isolation were 'settledmoderate' $(56.8 \% ; 50 / 88)$ - challenging the ERC's stated ambitions for higher risk-taking levels via its StG (see Section 1). However our types are relative to this particular respondent set so we cannot know how our 'settled-moderates' relate to novelty/risk-taking levels elsewhere in the global research community.

There were notable interactions between 'approach' and 'standing'. We found no 'nomadic-radicals' and few 'settled-radicals' in independent 'standing' conditions. This warrants further research but may suggest that a radical 'approach' and independent 'standing' are mutually exclusive or that 'radical' researchers achieve independence later in their careers.

Separately we observed less researcher type variety within our control group, and proportionally far more controls at our 'lower' boundaries, with $47.6 \%$ (10/21) of controls having 'settled-moderate' approach coupled to 'dependent-unprolific-normal' standing, compared with $24.4 \%(19 / 78)$ of grantees (Table 3). ${ }^{24}$ Our limited response numbers affect the significance of this finding but we can tentatively suggest two opposing interpretations: the ERC may have successfully selected for more variety and stronger frontier-potential characteristics; alternatively, it may have funded too many 'advanced' individuals, overlooking perhaps similar promise but not yet independent, control group researchers.

\section{Discussion and conclusions}

With our DAS framework we aimed to characterize researchers themselves rather than to look in isolation at the output of their labours. Our characterization took an integrated view of not only individual frontier-potential attributes and attitudes ('approach') but also experienced conditions/opportunities ('standing') - emphasizing that individual researcher attitudes/attributes in isolation may prove fruitless without particular contextual conditions/ opportunities. We thus considered a range of potential enabling/disabling factors and not just the role of funding in causing later impacts, and acknowledge researchers can create their own enabling conditions, above and beyond the funding they receive. We further made an initial contribution by empirically registering DAS characteristics that tentatively are applicable across a wide variety of research fields, and by creating varied grantee/ control matched-pairs and researcher types for our specific survey respondent set.
Our individual and aggregate researcher characterizations were intended primarily to provide us with a baseline measurement to prepare the ground for a later study of StG impact. For now our researcher types cover $56-71 \%$ of our survey respondents, and our individual characterization led to 19 grantee/control matched-pairs covering $18 \%(34 / 184)$ of our respondents. ${ }^{25}$ We have pairs in all three research domains (LS, PE, and SH) to permit later study of field-specific aspects, and pairs with varying characteristics to enable study of $\mathrm{StG}$ impacts from differing initial conditions.

Our types allow us to suggest intended (by the ERC) and expected (under our assumptions) StG impacts. These can be thought of as 'impact pathway' movements between our various researcher types. First, intended by the ERC but not expected by us, movement from 'settled' to 'nomadic' intellectual field mobility could occur, following more significant intellectual field changes by a researcher. Similarly moving from 'moderate' to 'radical' novelty/risk-taking could occur if a researcher starts riskier funded research projects addressing research lines breaking with past activity and regarded as non-mainstream by the research community.

Impact pathways between 'standing' types are intended by the ERC and are where we expect greatest StG impact. Movement from 'dependent' to 'independent' standing could occur, expressing greater ability to raise research resources, greater job security conducive to long-term research direction freedom, and more research resources (money, infrastructure, people). Moving from 'unprolific' to 'prolific' output productivity would require more time to do research and compose research outputs, and better conditions to undertake and exploit more significant research findings. Finally, moving from a 'normal' to an 'elite' research workplace could be achieved by improving existing conditions (one's own capacity or by internal negotiations and/or promotions) or moving to a new research workplace with better conditions (attribution of these impact pathways to the StG would of course require an observation of proportionally more grantees than controls following them after a repeat measurement, and similar effects for the grantee/control matched-pairs).

\subsection{Some limitations}

Our approach has several limitations. First we registered opinions and recalled facts as proxies for frontier-potential research activity. We have not directly characterized research content or outcomes. This aspect could be explored to bolster our characterization work via interviews with the researchers to analyse detailed changes to research trails (see Gläser and Laudel 2009; Laudel 2011; Laudel and Gläser 2012).

Second, our work is based on a limited number of respondents from one $\mathrm{StG}$ cohort that may have atypical features (as the first call of a new, flagship research 
funding agency). These matters limit the significance and generalizability of our findings. Further surveys of different populations of researchers, using the same approach, would be needed to indicate how our relative measures relate more generally to the wider population of 'starting' researchers in Europe. Third, our survey-based approach provided self-reported data, limiting the significance of our current findings and any later impact study.

\subsection{Future development}

In future we could map a greater range of local research environment factors, such as research group and leadership dynamics, researcher recruitment aspects, and research activity portfolios. We could also register and trace the respondent's own role, e.g., as research group member or leader, and their intellectual/group/leadership strategies. We might also study later StG cohorts, and separate researcher cohorts funded by other research agencies. This might improve the significance of our work and its generalizability across research field, country, and research organization settings. A final promising avenue, given that our survey approach was non-anonymous, would be to bolster our dataset by employing secondary sources (e.g. CV analysis, co-nominations of key researchers, prize winner lists ${ }^{26}$ ) and complementary non-invasive techniques, such as suitable bibliometric analyses of our existing respondent set.

Lastly, we look to complete the second stage of our proposed two-stage impact study. In particular our main finding that most grantees were in 'dependent-unprolific-normal' conditions that could conceivably be significantly altered by a funding scheme like the StG seems to warrant this future step.

\section{Acknowledgements}

This work is based on research from the EURECIA project (Understanding and Assessing the Outcomes of ERC Funding) sponsored by the ERC and funded by the FP7 Ideas Programme (grant number 229286). An earlier version was presented at the European Network of Indicator Designers (ENID) STI Indicators Conference, CERIS, Rome (Italy), 7-9 September 2011. The authors thank two anonymous reviewers for very helpful comments.

\section{Notes}

1. From <http://erc.europa.eu/index.cfm?fuseaction $=$ page.display\&topicID $=12>$ accessed 24 August 2011, emphasis added.

2. From <http://erc.europa.eu/index.cfm?fuseaction $=$ page.display\&topicID $=65>$ accessed 24 August 2011 .

3. From <http://erc.europa.eu/index.cfm?fuseaction $=$ page.display\&topicID $=65>$ accessed 24 August 2011 .
4. StG grantees can be any nationality but must be European residents.

5. For the first call in 2007, up to 9 years post-PhD; in 2011, 2-12 years post-PhD, to allow for recognized career breaks.

6. The first ERC StG call (2007) received 9,167 proposals, 299 were funded (3\% success rate); the second (2009), 2,503 proposals, 244 projects funded ( $10 \%$ success); the third (2010) 2,873 proposals, 427 funded (15\%); and the fourth (2011) 4,080 proposals with 480 funded (12\% success) (see http://erc.europa .eu/statistics, accessed 1 November 2011). The ERC notes the drop in applicants between the first and second call related to full proposals being required for the second call, where only short pre-proposals were needed for the first. Second (and subsequent) call applicants were also screened against 'benchmark' profile factors further reducing numbers. The low success rate of the first call might have deterred later call applicants, and the StG's perceived novelty had waned (ERCEA 2011). The ERC's annual budget increased year-on-year, permitting more projects to be funded in successive calls.

7. From http://erc.europa.eu/glossary/term/233, accessed 9 December 2011.

8. Even research that directly associates psychological states with creativity, e.g. autistic inventors and technological revolutions (Ravilious 2011) insufficiently considers environmental factors that may enable/disable creativity coming to fruition in society.

9. For instance Jordan et al. (2003) look at: strategy focus (goal-attainment, strategic stakeholder, systems, competing-values); people, leadership/management, and organization performance drivers; high-performing group/environment characteristics (good people, leadership/governance, and communication practices, good people/task fit, positive work motivations, and rewards, high autonomy, appropriate peer pressure, interdisciplinary, and organization by problem rather than discipline); research resource characteristics (good funds, time, talent, technicians, laboratory equipment/facilities, and support systems); and relational characteristics (knowledge of competitor research strategies/gaps, understanding how new intellectual developments affect existing research lines, and openness to research line shifts).

10. Jordan (2006) explains, after Afuah and Bahram (1995) that 'radical' change is subjective, depending on whether related knowledge and innovations exist, and whether innovator, user, supporting innovators, and suppliers consider it 'radical'.

11. There were reported difficulties integrating suddenly independent ENP researchers, often externally recruited, into German university career norms. There was also self-selection; few to no low-performing researchers applied for this high-status funding scheme, 
affecting prediction of applicants' success rates based on prior productivity/citation measures. The ENP attracted a 'special group of outstanding and promising young researchers' - a 'very homogeneous group of high performing scientists' (Böhmer and Von Ins 2009: 183-184).

12. The ATP supports US innovation via 'competitively awarded funding to companies pursuing early-stage high-risk Research and Development' (NIST 2003); although it involves industrial $\mathrm{R} \& \mathrm{D}$, the early-stage/ high-risk aspects were relevant.

13. The model of impact was based on sequential inputs, outputs, outcomes then impacts from ATP funding (NIST 2006). A survey of ATP applicants in 2004 (Kerwin and Campbell 2007) looked at overall chance of project success to gauge risk-taking levels - i.e., percentage risk of achieving minimum and more significant project goals (chance of project success).

14. These were the 2007 call StG categories. Later calls added a fourth 'interdisciplinary' domain (IR). Domain budgets have usually been pre-allocated, based on how national public research budgets typically fund them.

15. We have some evidence that our response set was representative of the wider 2007 cohort successful and quality-screened unsuccessful applicants (our responses match the original sample on key characteristics of gender balance, age mix, and distribution of research domains and ERC assessment sub-panels). There is also early indication that the descriptive characteristics of our respondents, such as a trend for high pre-StG but low post-StG geographic and workplace mobility, have been observed for later StG cohorts (e.g. the 2009 StG call cohort, see Huber and Böhmer 2011).

16. We explored in open survey questions the most significant geographic and cognitive moves, and reasons why particular journals were seen to be important.

17. Our use of the term 'standing' was deliberate to capture the prestige aspect of these conditions and settings.

18. This indicator classified respondents' current countries of residence as Tier 1 (highest performance/ambition), Tier 2 then Tier 3 (lowest). It covered 93\% (167/180, missing $=4$ ) of our survey respondents' reported current countries of residence.

19. At Stage 1 the scientific quality of the proposed is accepted so later rejection is unlikely due primarily to quality deficiencies.

20. A further 23 grantees and 20 controls either did not wish to be contacted, had already been interviewed during the EURECIA project, or were otherwise not contactable.

21. Later StG calls added a career stage differentiation'starters' (2-6 years post-PhD) and 'consolidators' (6-10 years post- $\mathrm{PhD})$.
22. Our DAS element S9 was found to be strongly positively correlated with these knowledge community career aspects: S6, amount of academic service tasks undertaken; S8, number of research collaborators; and S10, number of accolades.

23. For full details, see Thomas and Nedeva 2012.

24. Additionally reporting on 'approach' and 'standing' types in isolation $78.3 \%(18 / 23)$ of controls were 'settled-moderate' and $66.7 \%$ (16/24) of controls were 'dependent-unprolific-normal'.

25. Several controls were paired with multiple grantees; 5-8 identically matched DAS elements were used to create each pair, to allow both male-male and female-female pairs, and to preserve variety in the final selection of pairs.

26. For instance, for nanotechnology and human genetics, Youtie et al. (2012) compared early and mid-career organizational and institutional influences on later recognition of scientific creativity, using survey-based nominations of creative individuals, research prize winners, and $\mathrm{CV}$ analysis. We might also tap such data sources given we have names and affiliations in our dataset, to explore these predictor factors such as broad academic education, fast $\mathrm{PhD}$ completion, and track record of independent post-doctoral research (found to be associated with future recognition for early-career researchers) and fast job promotion, work experience, research leadership, external grant income, and prestigious prizes (found as mid-career researcher factors predicting later scientific recognition, more so in the USA than Europe, due to differing academic labour markets).

\section{References}

Afuah, A. N. and Bahram, N. (1995) 'The Hypercube of Innovation', Research Policy, 24: 51-76.

Andrews, R., ed. (1979) Scientific Productivity: The Effectiveness of Research Groups in Six Countries. Cambridge: Cambridge University Press.

Antonakis, J., Fenley, M. and Liechti, S. (2011) 'Can Charisma be Taught? Tests of Two Interventions', Academy of Management Learning \& Education, 10/3: 374-396.

Basalla, G. (1988) The Evolution of Technology (Reprinted in 1997). Cambridge: Cambridge University Press.

Bauer, H. et al. (2012) 'How does Scientific Success Relate to Individual and Organizational Characteristics? A Scientometric Study of Psychology Researchers in the German-speaking Countries', Scientometrics, doi:10.1007/ s11192-012-0760-3.

Bennis, W. and Biederman, P. W. (1997) Organizing Genius: The Secrets of Creative Collaboration. Reading, MA: Addison-Wesley.

Böhmer, S. and von Ins, M. (2009) 'Different - Not Just by Label: Research-oriented Careers in Germany', Research Evaluation, 18/3: 177-184.

Bourke, P. and Butler, L. (1999) 'The Efficacy of Different Modes of Funding Research: Perspectives from Australian 
Data on the Biological Sciences', Research Policy, 28: 489-499.

Boyatzis, R. E. (2008) 'Competencies in the 21st Century', Journal of Management Development, 27/1: 5-12.

Bozeman, B. and Gaughan, M. (2011) 'How do Men and Women Differ in Research Collaborations? An Analysis of the Collaborative Motives and Strategies of Academic Researchers', Research Policy, 40: 1393-1402.

Braben, D. W. (2004) Pioneering Research: A Risk Worth Taking. Hoboken, New Jersey: Wiley-Interscience.

Braun, D. (2012) ERC Impact on Funding Systems, (2012), EURECIA project discussion paper, January 2012, <http:// www.eurecia-erc.net/wp-content/upLoads/EURECIAImpactOnFundingSchemes.pdf $>$ accessed 30 Mar. 2012.

Burt, R. S. (1992) Structural Holes: The Social Structure of Competition. London: Harvard University Press.

- (2004) 'Structural Holes and Good Ideas', American Journal of Sociology, 110/2: 349-399.

Charlton, B. G. (2009) 'Why are Modern Scientists so Dull? How Science Selects for Perseverance and Sociability at the Expense of Intelligence and Creativity', Medical Hypothesis, 72: $237-243$.

Chen, C. (2012) 'Predictive Effects of Structural Variation on Citation Counts', Journal of the American Society for Information Science and Technology, 63/3: 431-449.

Clausen, T., Fagerberg, J. and Gulbrandsen, M. (2012) 'Mobilizing for Change: A Study of Research Units in Emerging Scientific Fields', Research Policy, 41/2012: 1249-1261.

Dill, D. (1982) 'The Structure of the Academic Profession: Towards a Definition of Ethical Issues', The Journal of Higher Education, 53/3: 255-267.

- (1985) 'Theory versus Practice in the Staffing of R\&D Laboratories', R\&D Management, 15: 227-241.

Dowd, K. O. and Kaplan, D. M. (2005) 'The Career Life of Academics: Boundaried or Boundaryless?', Human Relations, 58/6: 699-721.

European Commission (EC). (2005) Frontier Research: The European Challenge - High-level Expert Group Report. Belgium, Brussels: European Commission, DirectorateGeneral for Research, EUR21619.

European Research Council Executive Agency (ERCEA). (2011) Annual Report on the ERC Activities and Achievements in 2010. Brussels: European Commission, Directorate-General for Research and Innovation, EUR24717.

Feldman, M. P. and Kelley, M. R. (2001) Winning an Award from the Advanced Technology Program: Pursuing $R \& D$ Strategies in the Public Interest and Benefiting from a Halo Effect. Washington DC: US Department of Commerce, National Institute of Standards and Technology, NISTIR-6577.

Gläser, J. and Laudel, G. (2009) 'Identifying Individual Research Trails', In: Proceedings of the 12th International Conference on Scientometrics and Infometrics, 14-17 July, pp. 841-845, Rio de Janeiro, Brazil.

Hage, J. (2006) Radical Innovation and Institutional Change: French Biomedicine, 1888-1919, Annual Meeting of the American Association for the Advancement of Science, 17 February.

Heinze, T. (2008) 'How to Sponsor Ground-breaking Research: A Comparison of Funding Schemes', Science and Public Policy, 35/5: 302-318.

Heinze, T. and Bauer, G. (2007) 'Characterizing Creative Scientists in Nano-S\&T: Productivity, Multidisciplinarity, and Network Brokerage in a Longitudinal Perspective', Scientometrics, 70/3: 811-830.
Heinze, T. et al. (2007) 'Identifying creative research accomplishments: Methodology and results for nanotechnology and human genetics', Scientometrics, 70/1: 125-152.

- (2009) 'Organizational and Institutional Influences on Creativity in Scientific Research', Research Policy, 38: 610-623.

Huber, N. and Böhmer, S. (2011) Monitoring European Research Council's Implementation of Excellence: Focusing on Indicators for evaluation of the Starting Grant Program, Conference paper. Rome, Italy: ENID STI Conference, 7-9 September.

Jordan, G. (2006) 'Factors Influencing Advances in Basic and Applied Research: Variation due to Diversity in Research Profiles'. In: Hage, J. and Meeus, M. (eds) Innovation, Science, and Institutional Change, pp. 173-195. Oxford: Oxford University Press.

Jordan, G., Streit, L. D. and Matiasek, J. (2003) Attributes in the Research Environment that Foster Excellent Research: An Annotated Bibliography, SAND Report 2003-0132, Albuquerque, NM: Sandia National Laboratories.

Kerwin, J. and Campbell, S. (2007) Findings from the Advanced Technology Program's Survey of ATP Applicants 2004, Washington, DC, US Department of Commerce, National Institute of Standards and Technology, Economic Assessment Office (and Westat), July, NIST GCR 07-908.

Klavans, R. and Boyack, K. W. (2011) Scientific Superstars and their Effect on the Evolution of Science, Conference Paper. Rome, Italy: ENID STI Conference, 7-9 September.

Lamont, M. (2009) How Professors Think: Inside the Curious World of Academic Judgment. Cambridge, MA and London: Harvard University Press.

Langfeldt, L. (2001) 'The Decision-making Constraints and Processes of Grant Peer review, and their Effects on the Review Outcome', Social Studies of Science, 31/6: 820-841.

Larédo, P. and Mustar, P. (2000) 'Laboratory Activity Profiles: An Exploratory Approach', Scientometrics, 47/3: 515-539.

Laudel, G. (2005) 'Migration Currents among the Scientific Elite', Minerva, 43: 377-395.

_ (2006) 'The Art of Getting Funded: How Scientists Adapt to their Funding Conditions', Science and Public Policy, 33/7: 489-504.

. (2011) ERC Grants Shaping Research and Academic Careers: Lessons for Funding Intellectual Innovations, Conference Paper. Atlanta, GA: Atlanta Conference on Science and Innovation Policy, 15-17 September.

Laudel, G. and Gläser, J. (2008) 'From Apprentice to Colleague: The Metamorphosis of Early Career Researchers', Higher Education, 56/3: 387-406.

- (2012) The ERC's Impact on the Grantees' Research and their Careers, (2012), EURECIA Project Report, January 2012, <http://www.eurecia-erc.net/wp-content/upLoads/ EURECIA-ImpactOnResearchContentAndCareersSummaryReport.pdf $>$ accessed 30 Mar. 2012.

Lee, A. (2009) Helping New Postgraduates. Maidenhead, UK: Mc Graw Hill/Open University Press.

Melin, G. and Danell, R. (2006) 'The Top Eight Percent: Development of Approved and Rejected Applicants for a Prestigious Grant in Sweden', Science and Public Policy, 33/ 10: 702-712.

National Institute of Standards and Technology (NIST). (2003) Survey of ATP Applicants 2000. Factsheet Series. Washington, DC: US Department of Commerce, Technology Administration, June, NIST GCR 03-847.

- (2005) Survey of ATP Applicants 2002: ATP Funds High-Risk and Long-Term R\&D Projects. Factsheet Series. Washington, DC: US Department of Commerce, Technology Administration, June, NIST GCR 05-876. 
(2006) Measuring ATP Impact: 2006 Report on Economic Progress. Washington, DC: US Department of Commerce, Technology Administration, NIST GCR 06-899.

National Research Council (NRC). (2006) Evaluation of the Markey Scholars Program. Washington, DC: The National Academies Press.

Nedeva, M. (2011) From Europe with Love: Capacity and the Organisational Dynamics of Science. Conference Paper. Atlanta, GA: Atlanta Conference On Science and Innovation Policy, 15-17 September.

Nedeva, M. and Stampfer, M. (2012) 'From "Science in Europe" to "European Science", Science, 336/6084: 982-983.

Nedeva, M. (2012) 'Between the Global and the National: Organising European Science', Research Policy, doi:10.1016/ j.respol.2012.07.006.

Nemet, G. F. and Johnson, E. (2011) 'Do Important Inventions Benefit from Knowledge Originating in Other Technological Domains?', Research Policy, 41: 190-200.

Neufeld, J. and von Ins, M. (2011) 'Informed Peer Review and Uninformed Bibliometrics?', Research Evaluation, 20/1: 31-46.

Polanyi, M. (1969) Knowing and Being. Chicago: Chicago University Press.

Ravilious, K. (2011) 'Mental problems gave early humans an edge', New Scientist, 7 Nov. 2011.

Rowley, J. and McCulloch, A. (1999) 'Developing Research Capacity: Moving on', Scottish Journal of Adult and Continuing Education, 5/2: 106-116.

Rycroft, R. W. and Kash, D. E. (1999) The Complexity Challenge: Technological Innovation for the 21st Century. London: Pinter Publishers.

Schilling, M. A. and Green, E. (2011) 'Recombinant Search and Breakthrough Idea Generation: An Analysis of High Impact Papers in the Social Sciences', Research Policy, 40: 1321-1331.

Schyns, B. et al. (2011) 'Teaching Implicit Leadership Theories to Develop Leaders and Leadership: How and Why It can Make a Difference', Academy of Management Learning \& Education, 10/3: 397-408.

Shapira, P. and Kuhlmann, S., eds (2003) Learning from Science and Technology Policy Evaluation. Cheltenham, UK: Edward Elgar.
Shapira, P., J. Youtie and J. Rogers 2009. Blind matching versus matchmaking: Comparison group selection for highly creative researchers. CREA Project working paper. Atlanta, GA: Georgia Institute of Technology.

Simonton, D. K. (2004) Creativity in Science: Chance, Logic, Genius, and Zeitgeist. Cambridge, UK: Cambridge University Press.

- (1999) Origins of Genius: Darwinian Perspectives on Creativity. New York: Oxford University Press.

Small, H. (2004) 'Why Authors Think their Papers are Highly Cited', Scientometrics, 60/3: 305-316.

Small, H., Kushmerick, A. and Benson, D. (2008) 'Scientists' Perceptions of the Social and Political Implications of their Research', Scientometrics, 74/2: 207-221.

Thomas, D. and Nedeva, M. (2012) EURECIA Work Package 3 (WP3): Survey of Starting Independent Researchers, (2012), EURECIA Project Final Report, April 2012, <http://www .eurecia-erc.net/wp-content/upLoads/EURECIA-

SurveyOfStartingIndependentResearchers.pdf $>$ accessed 30 Apr. 2012.

Udwadia, F. E. (1990) 'Creativity and Innovation in Organizations: Two Models and Managerial Implications', Technological Forecasting and Social Change, 38: 65-80.

Vallerand, R. J. et al. (1992) 'The Academic Motivation Scale: A Measure of Intrinsic, Extrinsic and Amotivation in Education', Educational and Psychological Measurement, 52: 1003-1017.

Van den Besselaar, P. and Leydesdorff, L. (2009) 'Past Performance, Peer Review and Project Selection: A Case Study in the Social and Behavioral Sciences', Research Evaluation, 18/4: 273-288.

Van Bouwel, L., Lykogianni, E. and Veugelers, R. (2011) Mobility of European Researchers to the US: Student and Researcher Mobility. Conference Paper. Rome, Italy: ENID STI Conference, 7-9 September.

Whitley, R. (2000) The Intellectual and Social Organization of the Sciences, 2nd edn. Oxford: Oxford University Press.

Youtie, J. et al. (2012) 'Career-based influences on scientific recognition in the United States and Europe: Longitudinal evidence from curriculum vitae data', Working Paper, Georgia Tech Program in Science, Technology and Innovation Policy, Atlanta, GA, USA. <http://works. bepress.com/pshapira/49> accessed 21 August 2012. 